\title{
Diagnostic imaging and cataloguing of female genital malformations
}

\author{
Pedro Acién ${ }^{1,2,3,4}$ - Maribel Acién ${ }^{1,2,3}$
}

Received: 3 May 2016 /Revised: 13 July 2016/Accepted: 20 July 2016/Published online: 9 August 2016

(C) The Author(s) 2016. This article is published with open access at Springerlink.com

\begin{abstract}
To help physicians and radiologists in the diagnosis of female genito-urinary malformations, especially of complex cases, the embryology of the female genital tract, the basis for Müllerian development anomalies, the current classifications for such anomalies and the comparison for inclusion and cataloguing of female genital malformations are briefly reviewed. The use of the embryological system to catalogue female genito-urinary malformations may ultimately be more useful in correlations with clinical presentations and in helping with the appropriate diagnosis and treatment. Diagnostic imaging of the different genito-urinary anomalies are exposed, placing particular emphasis on the anomalies within group II of the embryological and clinical classification (distal mesonephric anomalies), all of them associated with unilateral renal agenesis or dysplasia. Similarly, emphasis is placed on cases of cervico-vaginal agenesis, cavitated noncommunicated uterine horns, and cloacal and urogenital sinus anomalies and
\end{abstract}

Pedro Acién

acien@umh.es; acien_ped@gva.es

Maribel Acién

macien@hotmail.com; macien@umh.es

1 Department of P.H., Sc.H. and Gynecology/Division of Gynecology, Miguel Hernández University, San Juan Campus, 03550 San Juan, Alicante, Spain

2 Obstetrics and Gynecology Service, San Juan University Hospital, San Juan, Spain

3 Institute of Gynecology PAA, Alicante, Spain

4 Departamento de Salud Pública, Historia de la Ciencia y Ginecología/Area de Ginecología, Facultad de Medicina de la Universidad "Miguel Hernández", Campus de San Juan, 03550 Alicante, Spain malformative combinations, all of them complex malformations. Diagnostic imaging for all these anomalies is essential. The best imaging tools and when to evaluate for other anomalies are also analysed in this review.

\section{Teaching points}

- The appropriate cataloguing of female genital malformations is controversial.

- An embryological classification system suggests the best diagnosis and appropriate management.

- The anomalies most frequently diagnosed incorrectly are the distal mesonephric anomalies (DMAs).

- DMAs are associated with unilateral renal agenesis or renal dysplasia with ectopic ureter.

- We analyse other complex malformations. Diagnostic imaging for these anomalies is essential.

Keywords Female genital malformations · Classification . Cataloguing $\cdot$ Diagnostic imaging $\cdot$ Complex malformations

$\begin{array}{ll}\text { Abbreviations } & \\ \text { US } & \text { Ultrasound (two- and three-dimensional) } \\ \text { CT } & \text { Computed axial tomography } \\ \text { MR } & \text { Magnetic resonance image } \\ \text { HSG } & \text { Hysterosalpingography } \\ \text { IVP } & \text { i.v. pyelography } \\ \text { TVU } & \text { Trasvaginal ultrasound } \\ \text { TRU } & \text { Transrectal ultrasound } \\ \text { ASRM } & \text { American Society for Reproductive } \\ & \text { Medicine } \\ \text { MRKH } & \text { Mayer-Rokitansky-Kuster-Hauser } \\ \text { ESHRE/ESGE } & \text { European Society for Human } \\ & \text { Reproduction and Embryology/ }\end{array}$


European Society for

Gynaecological Endoscopy

\section{Introduction}

It is important to identify abnormalities of the female reproductive tract as they are associated with a range of gynaecological and obstetric problems. Complex malformations, such as mesonephric and some Müllerian anomalies and also cloacal or urogenital sinus anomalies and malformative combinations, are especially important because in addition to creating fertility problems, they cause clinical symptoms and impact the quality of life, especially in young women. The overall prevalence of these disorders may be as high as 3 to $6 \%$ and even higher in certain groups of women [1-3]. Today, there is increased detection caused by increased utility of imaging. The magnetic resonance image (MR) is the imaging standard of reference because it is non-invasive, does not involve ionising radiation, has multiplanar capability, allows excellent soft-tissue characterisation and permits a greater field of interrogation than ultrasound (US) (2D and 3D) [4-6]. However, other authors [7] believe that US (3D) could replace MR as the new gold imaging standard in diagnosing Müllerian anomalies.

Imaging and cataloguing of female genital malformations are important, but have the following prerequisites: (1) knowledge of the embryology of the female genito-urinary tract and interaction between the Wolffian/Müllerian ductal systems; (2) knowledge of anomalies involved in the classical Müllerian development as well as the septum resorption processes. Thus, to alert and help the physicians, especially radiologists, in diagnosing female genito-urinary malformations, these mentioned aspects will be reviewed briefly as well as the clinical presentation, catalogation and inclusion of female genital malformations in the embryological and clinical classification [8] and in other current classification systems. Finally, diagnostic imaging for all female genito-urinary malformations is presented with emphasis on the more complex anomalies, which are better understood on this embryologic basis, in other words, according to the updated embryological and clinical classification of female genitourinary malformations [8].

\section{Embryology}

Figure 1 shows schemes of female genito-urinary embryology [8-11]. Briefly, the uterus is formed from the fusion of the distal segments of Müller's ducts and the later reabsorption of the intermediate wall, whereas the vagina proceeds from the Wolffian ducts and Müllerian tubercle [9, 11]. The appropriate development, fusion and resorption of the wall that separates both Müller ducts are induced by the Wolffian ducts located at both sides, which act as guide elements. Moreover, since the ureteral bud sprouts from the opening of the Wolffian duct into the urogenital sinus, the absence or distal injury of one of these ducts will give rise to renal agenesis, ipsilateral blind or atretic hemivagina and a uterine anomaly (fusion or resorption defect). Other embryological considerations can be seen in different articles [8-15]. Müllerian development anomalies

In terms of the classical Müllerian development processes, it is important to distinguish the following:

(1) Anomalies caused by total or partial agenesis of one (unicornuate uterus) or both Müllerian ducts [MayerRokitansky-Kuster-Hauser (MRKH or Rokitansky syndrome].

(2) Anomalies caused by total or partial absence of fusion (didelphys uterus and bicornuate-bicollis and unicollisuterus).

(3) Anomalies caused by total or partial absence of reabsorption of the septum between the Müllerian ducts (septate and subseptate uterus).

(4) Anomalies caused by a lack of later development [hypoplastic uterus, T-shaped and diethylstilbestrol exposure (DES) syndrome] [15].

This classification system for uterine malformations is followed by the traditional classifications [5, 16-20] and the most recent cataloguing systems [21, 22]. However, several published cases showing a septate uterus with double cervix and vagina and normal uterus with septate cervix and vagina [23-25] questioned the classic hypothesis of unidirectional Müllerian development and supported the alternative embryologic hypothesis of Müller et al. [26], which states that fusion and resorption begin at the isthmus and proceed simultaneously in both the cranial and caudal directions.

These reported cases [23-25] and others [14] appear to prove the existence of a possible discrepancy in the processes of fusion and resorption between the superior-convergent and the inferior-divergent portions of the Müllerian ducts. Therefore, malformations can range from the didelphysunicollis uterus to the bicervical normal uterus or normal uterus with a septate cervix and/or vagina [8, 14, 27]. The latest ESHRE/ESGE classification system "UCV" [21, 22] is also based on these Müllerian development processes, but considers uterine, cervical and vaginal anomalies, with anatomy being the basis for the systematic categorisation of female genital malformations.

\section{Comparison for inclusion and cataloguing of female genital malformations}

The main classification systems for genital malformations refer to only Müllerian anomalies or the anatomic visual 

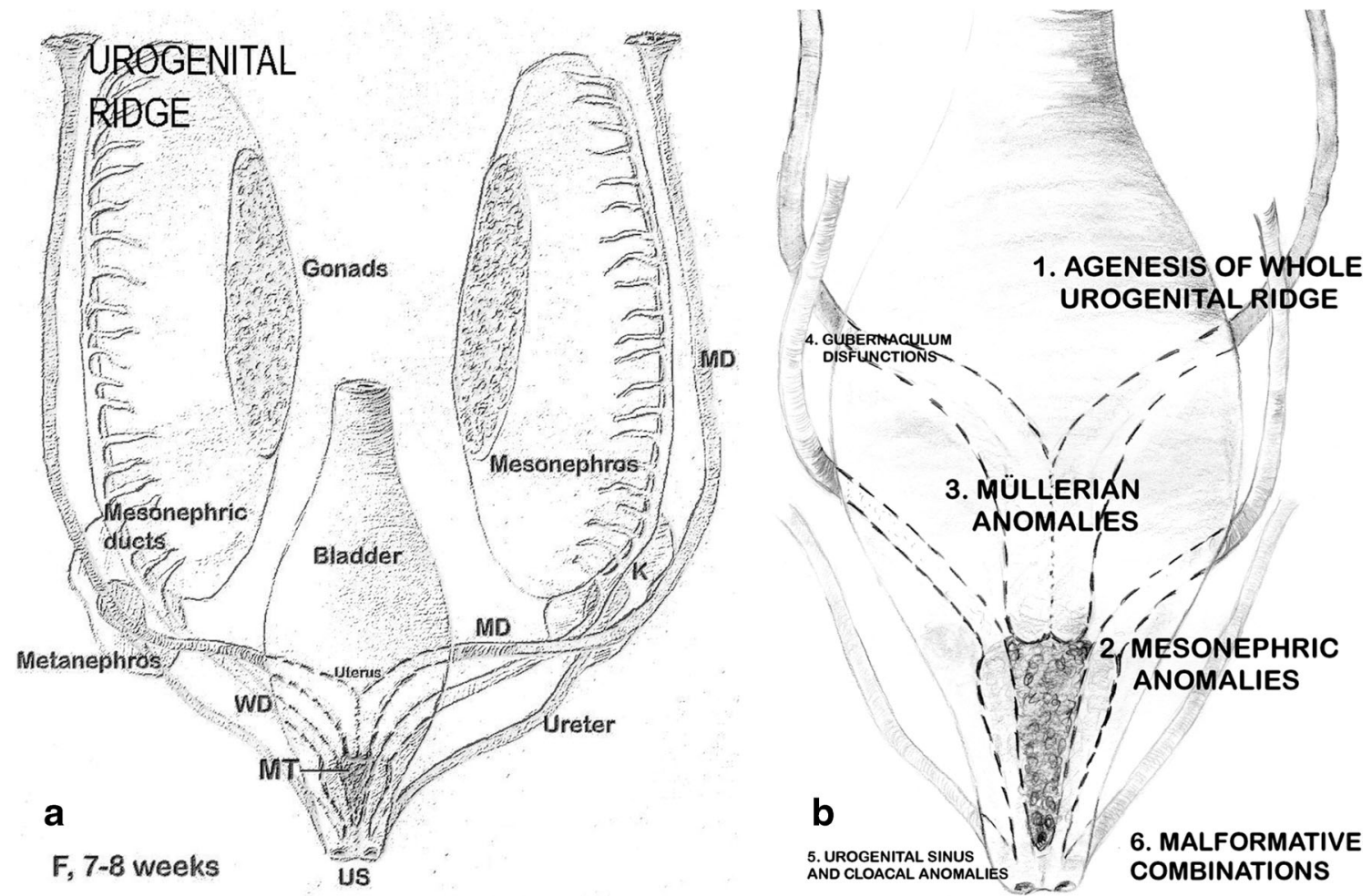

Fig. 1 Embryology of the female genito-urinary tract. a Development of the genital ducts in the female (frontal view, 7-8 weeks). The formation of the uterine primordium and the opening of the mesonephric ducts into the urogenital sinus are shown. The Müllerian tubercle can be seen between both Wolffian ducts and the ureteral buds sprouting from the opening of the Wolffian duct into the urogenital sinus. MD, Müllerian ducts; WD,

appearance and do not explain or suggest the actual origin of female genito-urinary tract malformations or their appropriate therapeutic correction. However, the embryological and clinical classification [8-10] correlates better among vaginal anomaly, uterine anomaly, and ipsilateral renal agenesis or renal dysplasia with or without ectopic ureter, suggesting the origin and possible clinical presentation and thus leading the diagnostic imaging.

Table 1 shows the congenital malformations of the female genito-urinary tract, their clinical presentation and cataloguing with the embryological and clinical classification [8] and also with the current classification systems [19, 22].

\section{Diagnostic imaging}

Based on our experience and an updated literature review, the clinical presentation and different diagnostic imaging tools are briefly analysed for each female genital malformation.

1. Agenesis or hypoplasia of a urogenital ridge: In these cases, there will be absence of the kidney, ureter, ovary, fallopian tube, hemiuterus and hemivagina (not

Wolffian ducts; K, kidney; MT, Müllerian tubercle; US, urogenital sinus. b On a diagram of the embryology of the female genital tract, the places and suggested pathogenesis for the origin of the different groups of malformations included in the embryological and clinical classification $[8,10]$ are shown

detectable) on one side (Fig. 2). Clinically, the most common presentation is a unicornuate uterus without a rudimentary horn or contralateral tube and ovary. This condition is sometimes associated with skeletal and/or auditory anomalies [28]. If there is also contralateral Müllerian agenesis, the diagnosis will be Rokitansky syndrome with unilateral renal agenesis [29] or atypical Rokitansky (Fig. 2b). MR is the best diagnostic tool, eventually complemented with hysterosalpingography (HSG) if unicornuate uterus is present. Also, transrectal ultrasound (TRU), i.v. pyelography (IVP) and computed axial tomography (CT) might help. It should be noted that renal agenesis occurs because of lesions of the urogenital ridge and not because of Müllerian agenesis.

2. Distal mesonephric anomalies, including unilateral renal agenesis and ipsilateral blind or atretic hemivagina syndrome: These are the most complex malformations; they include uterine duplicity (didelphys, bicornuate or less commonly septate uterus), renal agenesis (or dysplasia with or without ectopic ureter) and any of the following subtypes: (a) large haematocolpos in a blind hemivagina, (b) "Gartner's duct pseudocyst" in the anterolateral wall of the permeable vagina, (c) partial 


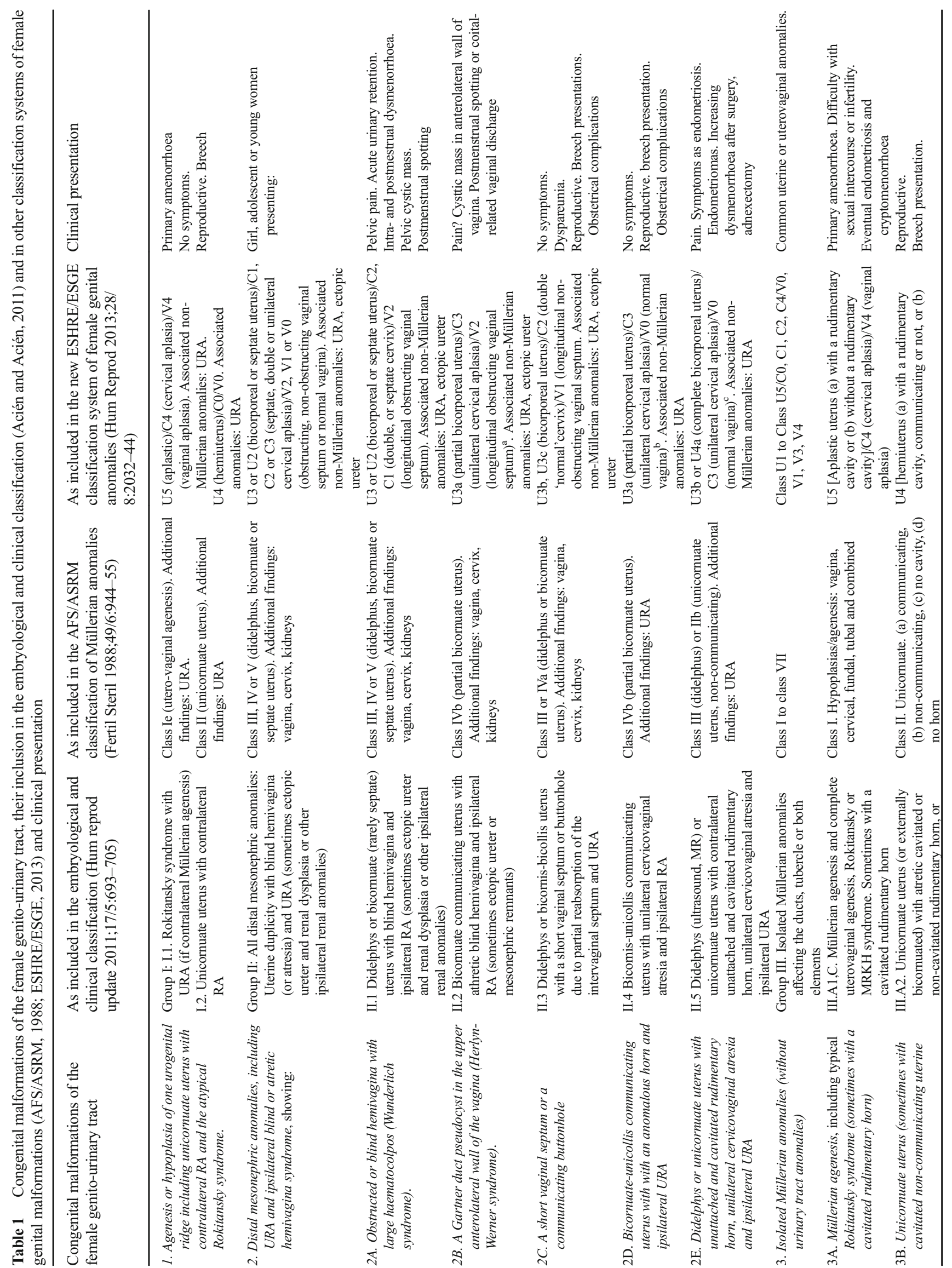




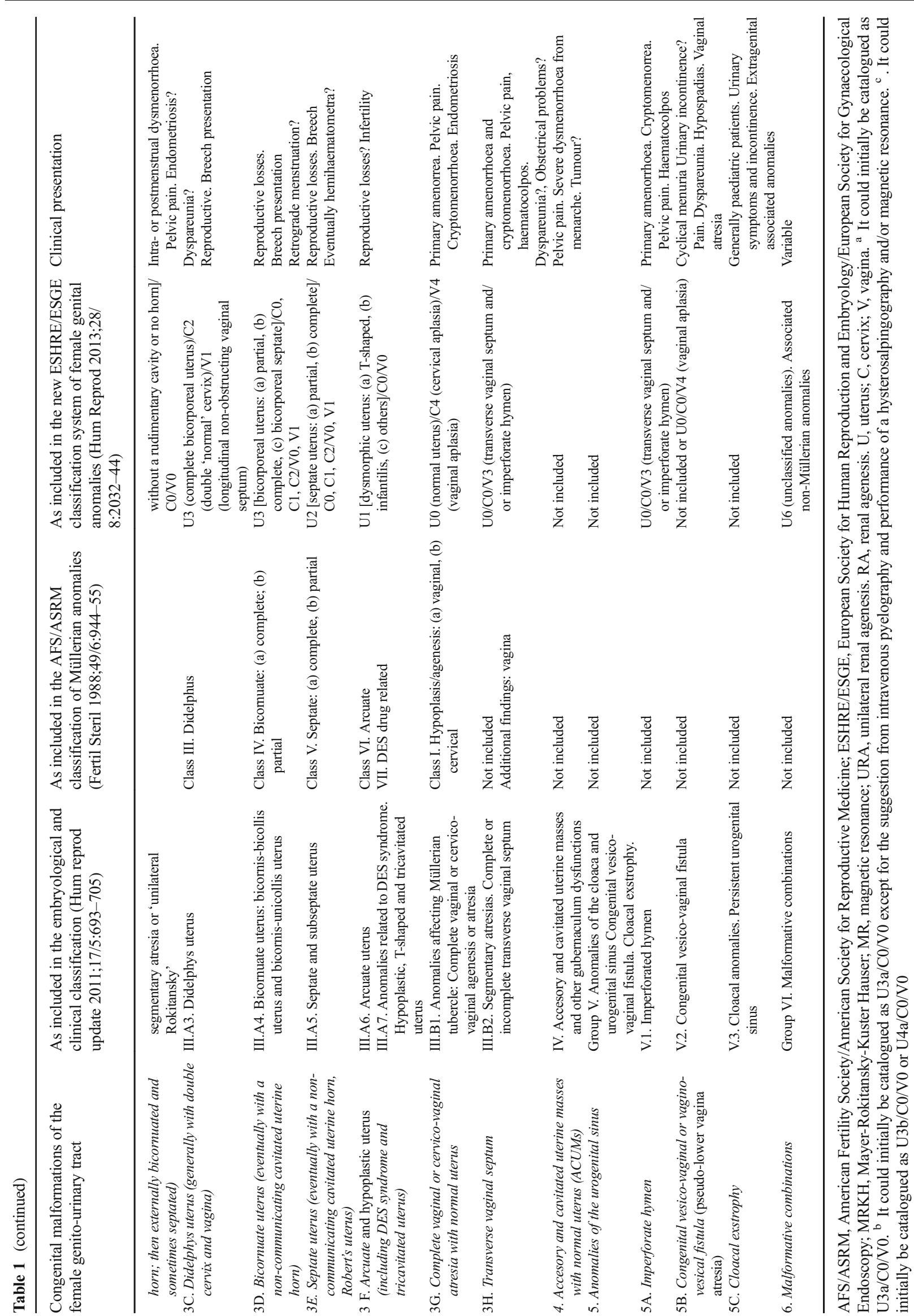


Fig. 2 Cases with agenesis or hypoplasia of the urogenital ridge. a Schematic representation and HSG showing right unicornuate uterus and agenesis of all derived organs of the left urogenital ridge. b Schematic representation and MR in a patient with agenesis of the right urogenital ridge andleft Müllerian duct (Rokitansky syndrome with unilateral renal agenesis). The T2-weighted MR image shows a medial sagittal plane with absence of the uterus and vagina $(<<)$. RO, Right ovary; LO, left ovary; RK, right kidney; LK, left kidney

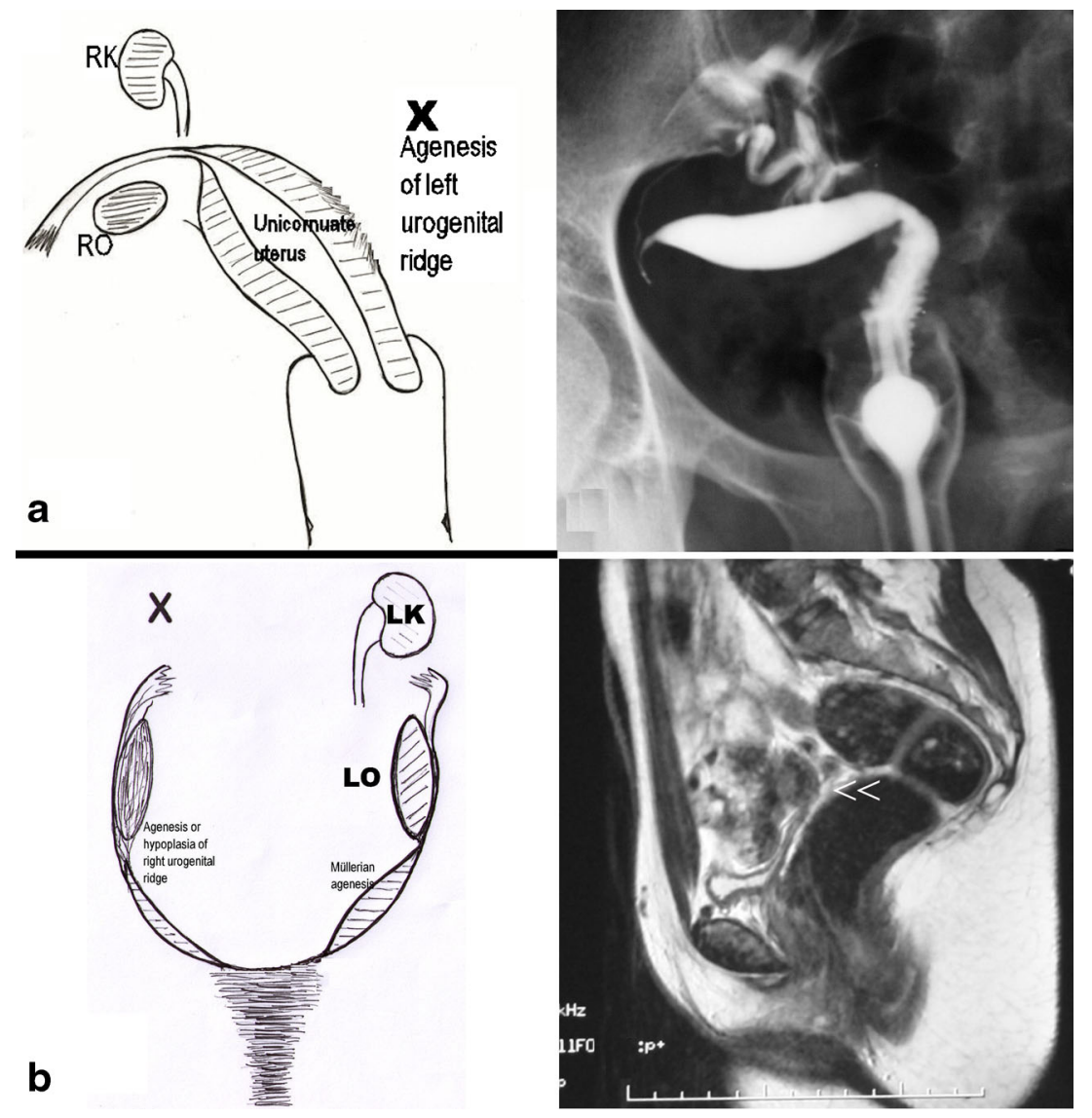

reabsorption of the intervaginal septum or (d) complete unilateral vaginal or cervicovaginal agenesis, with or without communication between both hemiuteri.

2a. Cases with unilateral haematocolpos (in girls, hydrocolpos) $[30,31]$ clinically manifest as progressive intra- and postmenstrual dysmenorrhoea present from menarche. On examination, a lateral and anterior bulge is revealed in the vagina. If haematocolpos is suspected, abdominal, transrectal or transvaginal ultrasound (TVU) can greatly aid the diagnosis, and when IVP and cystoscopy show renal agenesis, the diagnosis is confirmed [15]. Nowadays, an adequately interpreted MR can be conclusive (Fig. 3a). Sometimes, there might be an interuterine communication (at the isthmus level) or intervaginal apex (Fig. 3b). Also, an ectopic ureter opening into the blind vagina can exist [32] and because communication between both sides is common, the symptom is permanent urinary incontinence between normal micturitions. The injection of a contrast agent into the blind hemivagina will allow the identification of the ectopic ureter by retrograde filling [32, 33] (Fig. 3c); 3D-US (Fig. 3d) and MR might be the main diagnostic tools, but the mentioned aspects and the radiographic images after retrograde filling must be considered.

2b. Patients with "Gartner duct pseudocyst" frequently have no symptomatology other than the fertility problems related to a communicating bicornuate uterus. Examination may reveal a cystic mass with the appearance of a Gartner cyst in the upper anterolateral wall of the vagina. This mass is actually an atretic blind hemivagina [34]. The corresponding hemicervix is usually atretic and the HSG can show a bicornuate-unicollis uterus due to communicating uteri. In other cases it can also be appreciated that the atretic hemicervix is permeable, fistulous and communicates with the atretic blind vagina. These cases correspond with the Herlyn-Werner syndrome [35]. MR and 3D-US could also provide an appropriate diagnosis.

2c. Cases with partial reabsorption of the intervaginal septum are similar to the didelphys uterus with a double cervix and vagina, but with unilateral renal agenesis.

2d. Cases with complete unilateral vaginal or cervicovaginal agenesis, ipsilateral to the renal agenesis, can have communication between 

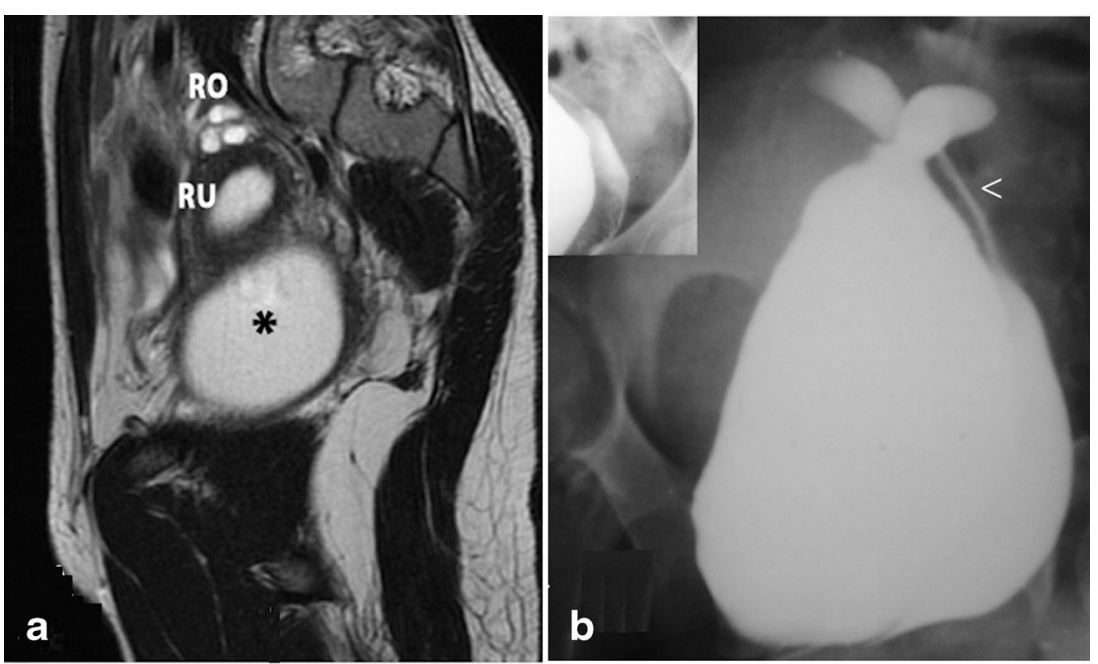

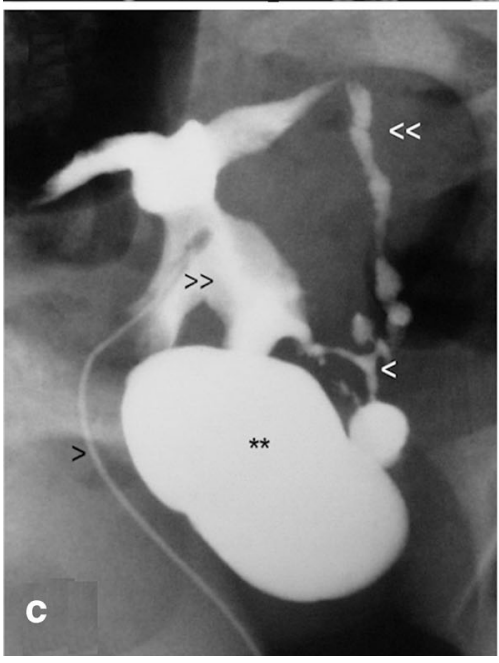

Fig. 3 Distal mesonephric anomalies with unilateral blind hemivagina and ipsilateral renal agenesis. a MR image corresponding to a 16-year-old patient suffering from strong dysmenorrhoea. After clinical examination and MR, she was diagnosed with endometrioma. However, a dydelphys uterus and right haematocolpos (*) can be observed. T2-weighted MR image, sagittal plane. RO, Right ovary; RU, right hemiuterus (taken from Acién and Acién, Hum Reprod Update 2016;22:48-69, figure 1A1, with permission). b An 18-year-old patient presenting with unilateral haematocolpos. Colpo-hysterography after injection of a contrast agent in the right blind hemivagina showing the contrast output through an interuterine communication and left hemivagina $(<)$. $\mathbf{c}$ Ectopic ureter.

both hemiuteri and will present as a bicornuateunicollis uterus (communicating uteri). See MR and $\mathrm{CT}$ in Fig. 4.

2e. In other cases, there is no communication between the hemiuteri. These cases reflect unilateral haematometra and endometriosis caused by retrograde menstruation on the side of the absent vagina and kidney [36, 37]. Differential diagnosis must be done with Müllerian segmentary atresias [38]. The 2D- and 3D-US, IVP and MR can help in the diagnosis and treatment includes a hemi-hysterectomy [15].

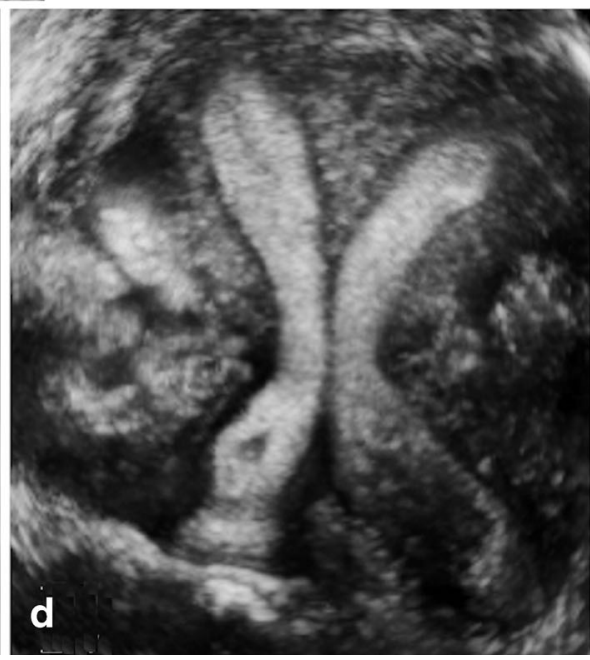

HSG image obtained with a small Foley catheter (>) showing the findings in a patient who underwent previous adhesiolysis and Strassman operation abroad. Left blind hemivagina (**), communicating uteri $(>>)$, left ectopic ureter $(<<)$ and possible mesonephric remnants $(<)$ can be observed (modified from Acién et al., Eur J Obstet Gynecol Reprod Biol 2004;117:105-108, with permission). d Three-dimensional ultrasound image showing a septate uterus and left blind hemivagina (now perforated) 1 year after drainage of haematocolpos and haematometra (courtesy of Dr. M. Sánchez Ferrer, Murcia)

3. Isolated Müllerian anomalies (without urinary tract anomalies): These include cases of:

3a. Müllerian agenesis, presenting: (a) vaginal agenesis with a functional uterus, (b) cervical agenesis, (c) uterine fundal or corporal agenesis and (d) tubal agenesis. These are rare anomalies, with 3D-US and MR being highly efficient in the diagnosis of anomalies of the cervix and vagina [39]. However, the combined uterovaginal agenesis is the most common type of agenesis (bilateral Müllerian agenesis) and it corresponds with MRKH or Rokitansky 
Fig. 4 Patient (32 years old) with complete unilateral vaginal or cervicovaginal agenesis or atresia and huge endometrioma. a T2weighted MR image showing a bicornuate (transitional or bicorporeal septate) uterus with communication at the ithsmic level $(<<$ ), septate cervix (very thin) with left cervicovaginal atresia (<). At the examination she had only a cervical external os (right side) and also severe endometriosis with great right endometrioma (shown in B). b Right endometrioma. $\mathbf{c}$ CT showing the bicornuate uterus and the cyst (endometrioma). d CT showing the left renal agenesis
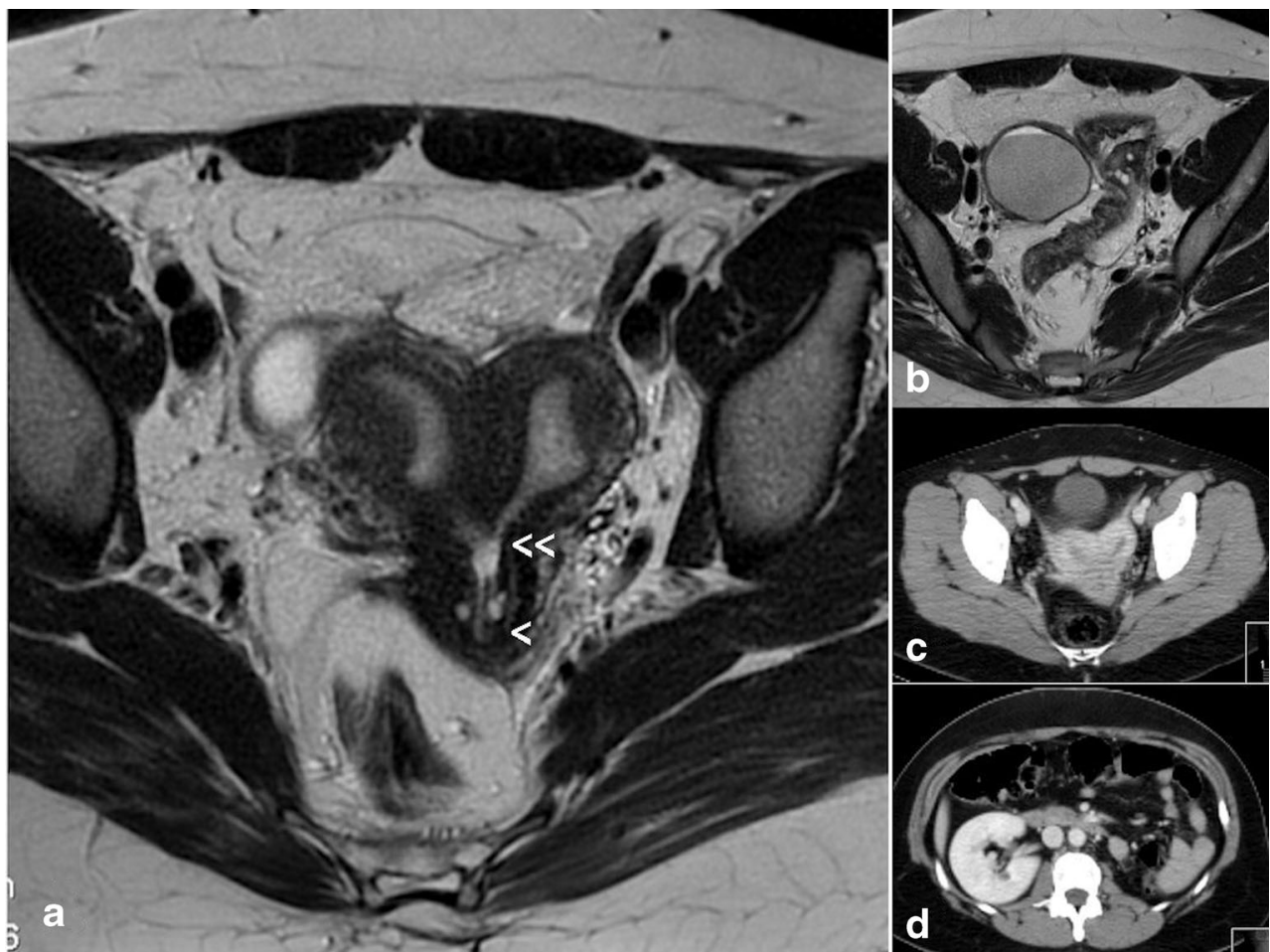

syndrome [40, 41]. This is an isolated Müllerian anomaly affecting both the Müllerian tubercle and ducts (Fig. 5a). Patients report primary amenorrhoea. TRU, CT or MR [42] demonstrate uterus absence with normal ovaries and two solid rudimentary horns. Some of these rudimentary horns may occasionally present a small functioning endometrial cavity, giving rise to retrograde menstruation and endometriosis [15, 43, 44]. Occasionally, the cavitated rudimentary horn might be well developed, with its reimplantation in a previously performed neovagina being possible $[15,45]$.
Fig. 5 Rokitansky syndrome and unicornuate uterus. a (1) CT in a patient with Rokitansky syndrome showing the uterovaginal rudimentary area under the bladder $(<<)$. (2) Showing both normal kidneys. b Patient with a unicornuate uterus and cavitated rudimentary uterine horn. (1) Axial and (2) T2weighted MR image (coronal cut) showing the left cavitated and rudimentary uterine horn $(<)$. *Left retrocervical subperitoneal serous cyst corresponding to a Müllerian remnant (excised during laparoscopy). (Modified from Acién and Acién, Hum Reprod Update 2016;22:48-69, Fig. 3b, with permission.) The i.v. pyelography showed normal kidneys
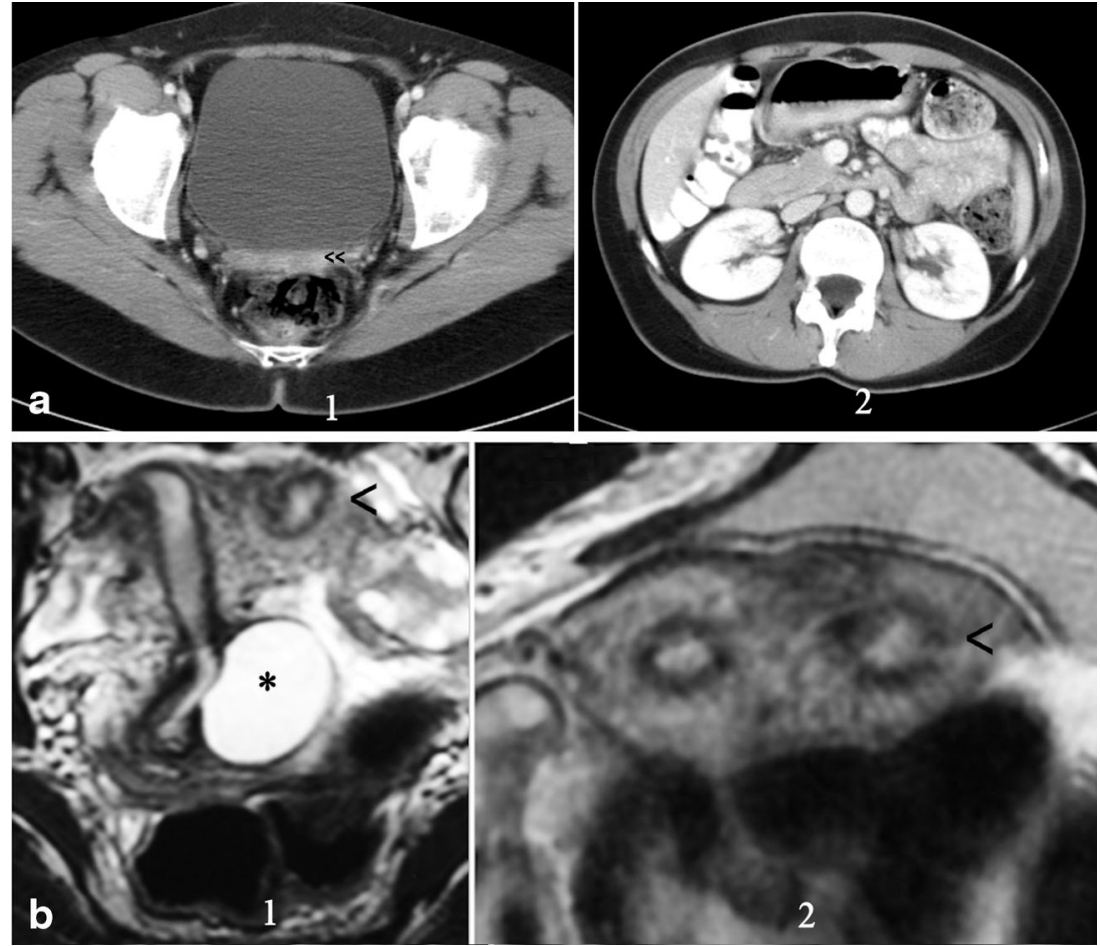
3b. Unicornuate uterus comes in several variations, based on the degree of development and absence of communication to the contralateral side (Fig. 5b). It can be easily diagnosed with HSG, but attention must be given for the possibility of a didelphys uterus with unilateral canalisation and contrast injection. Nowadays, 3D-US is a better tool and MR is of special interest in the detection of a cavitated non-communicated uterine horn, which can also be observed with TVU. It must be remembered that in all isolated Müllerian anomalies both kidneys will be present.

3c. Didelphys uterus presents two completely detached hemiuteri (like two unicornuate uteri) with two cervices and a double vagina. The new ESHRE/ESGE classification system [22] has assimilated the didelphys to bicornuate uterus, including it as a complete bicorporeal uterus (U3/C2/V2). For the diagnostic imaging, the considerations made on the resorption of the septum and the bidirectional hypothesis of Müller et al. [26] have to be taken into account, and cases with a didelphic uterine corpus and simple (normal or septate) cervix and vagina can be found.

3d. Bicornuate uterus (Fig. 6a) includes complete (bicornis-bicollis uterus) and partial (bicornis- unicollis uterus) in the AFS/ASRM classification [19] or partial, complete and bicorporeal septate uterus in the new ESHRE/ESGE classification [22]. Some cases can have a cavitated noncommunicating horn, and their inclusion as a bicornuate/septate or unicornuate uterus is discussed (see Fig. 5b). Currently, sonohysterography, 3D-US and specially the MR may provide the differential diagnosis with the septate uterus without the need of laparoscopy. In a pelvic MR, a significant fundal cleft $(>1 \mathrm{~cm})$ indicates no fusion of the upper-mid uterine horns [19, 46]. However, if this distance measures less than $1 \mathrm{~cm}$, then a septate uterus would be present [46]. In the ESHRE/ESGE classification system [22], class U3 (bicorporeal uterus) is defined by an external indentation of $>50 \%$ of the uterine wall thickness, whereas in the complete bicorporeal uterus (U3b), the width of the fundal indentation at the midline is $>150 \%$ of the uterine wall thickness.

3e. Septate uterus (complete and partial or subseptate uterus) (Fig. 6b). The diagnosis is equally suggested by TVU and $3 \mathrm{D}-\mathrm{US}$ or by HSG. Currently, sonohysterography, 3D-US, CT and specially MR can provide the appropriate differential diagnosis [4-7, 47]. Imaging description for septate uterus in the AFS/ASRM classification (class V) is convex,
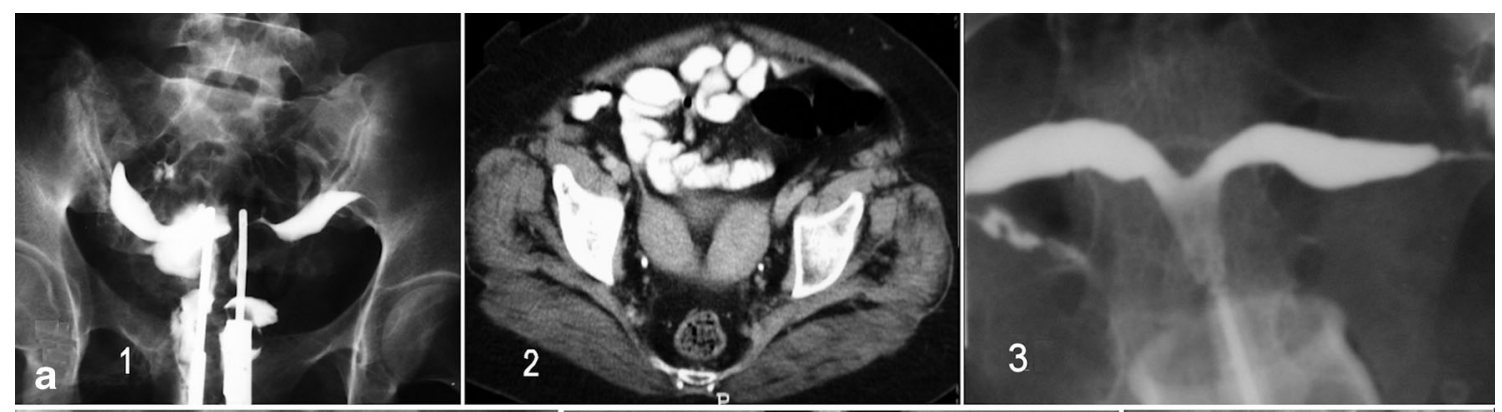
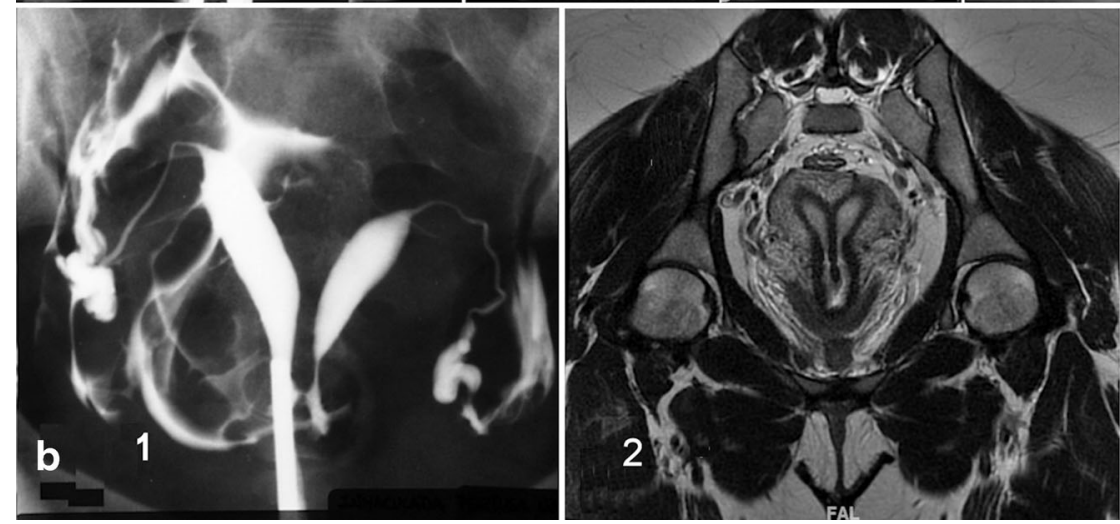

using a single cannula through the right side. 2 T2-weighted MR image in a 29 -year-old patient showing a septate uterus with septate cervix but single external os and vagina. Coronal plane. 3 HSG of a subseptate uterus

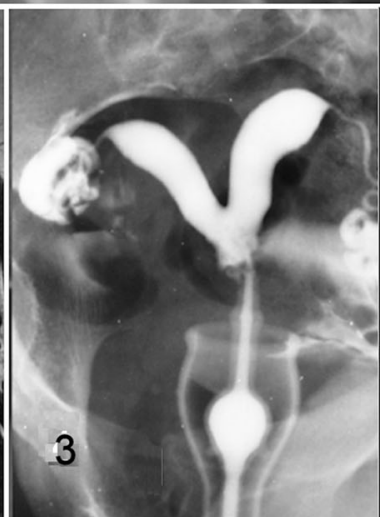

Fig. 6 Didelphys, bicornuate and septate uteri. a 1. HSG image of a patient with didelphys uterus obtained using a double simultaneous cannula. 2. CT of other patient showing a bicornuate uterus. 3. HSG image of a bicornis-unicollis uterus. b 1 HSG showing a complete septate uterus and communicating septate uterus. HSG was obtained 
flat or minimally indented $(<1 \mathrm{~cm})$ fundal contour with indentation of the myometrium/septum into the uterine cavity $(>1 \mathrm{~cm})$ [46]. In the ESHRE classification [22], class U2 (septate uterus) is considered by an internal indentation $>50 \%$ of the uterine wall thickness and external contour straight or with indentation $<50 \%$ [21, 22].

3f. Arcuate uterus is a minor form of bicornuate uterus. It has not been included in the new ESHRE/ESGE classification system [22].

3g. Anomalies related to DES syndrome include hypoplastic, tricavitated and T-shaped hypoplastic uteri with an extremely small uterine cavity, cornual constrictions and bulbous dilatation of the lower segment. In the new ESHRE/ESGE classification [22], these anomalies are included as dysmorphic uterus (class U1).

3h. Isolated Müllerian anomalies affecting the Müllerian tubercle include: (1) complete vaginal (or cervicovaginal) agenesis or atresia and (b) segmentary atresias, as in cases of transverse vaginal septum.

Complete vaginal or cervicovaginal agenesis or atresia with a functional uterus is usually a complex malformation in which the external genitals and tubes appear normal. The uterus may be normal or may present with fusion or resorption defects and the cervix may be present, absent or hypoplastic. The clinical presentation involves primary amenorrhoea and cyclic pain in postpubertal women. TRU and particularly MR (Fig. 7) allow a clear diagnosis that includes a largely normal corpus uteri with endometrium and cervicovaginal atresia. The ovaries are normal, although they might present endometriosis because of retrograde menstruation. Laparotomy with atretic cervix resection and reimplantation of the uterine corpus in the neovagina is recommended, having achieved normal menstruations and spontaneous term pregnancy $[15,48]$.

Vaginal segmentary atresia and transverse vaginal septum correspond to a transverse constriction or septum that is perforated or imperforated. There may be no symptoms until puberty when the haematocolpos forms and causes episodes of pelvic pain and primary amenorrhoea similar to those observed with vaginal atresia $[49,50]$. The examination, abdominal or TRU and specially MR allow the diagnosis and help on the surgical evacuation of the haematocolpos. Uterus, fallopian tubes and ovaries are usually normal.

4. Gubernaculum dysfunctions: These cases are typified by accessory and cavitated uterine masses (ACUMs) with an otherwise normal uterus [51-53]. HSG will show a normal endometrial cavity and 3D-US and especially MR allow the right diagnosis.

5. Anomalies of the cloaca and urogenital sinus (including congenital vagino-vesical fistulas): This category includes cases as simple as the imperforate hymen due to a persistent urogenital membrane together with blind hemibladder [54], bladder duplication [55, 56], bilateral single system ectopic ureters opening into the vestibule or a vaginalised urogenital sinus with bladder agenesis or hypoplastic bladder [57-59] or congenital vesicovaginal or vesico-uterine fistulas (pseudofistula with menuria $[60,61])$ and cloacal exstrophy $[62,63]$ (Fig. 8). Diagnosis can be made with the physical examination together with TRU, IVP (eventually, retrograde pyelogram), cystouretroscopy, cystography, CT, and specially MR, or abdominal US for prenatal diagnosis [56, 64].

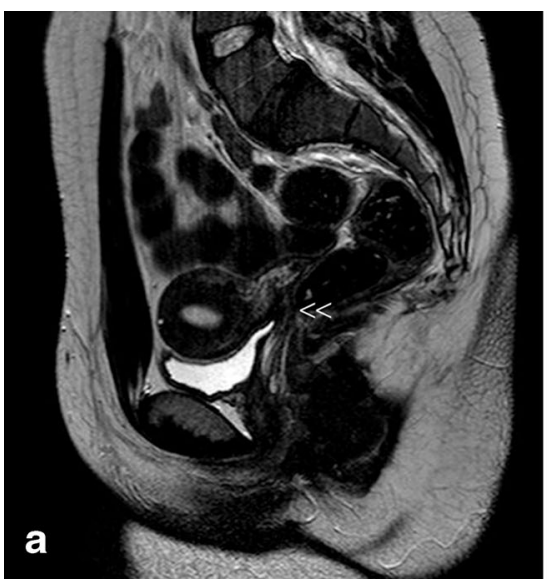

Fig. 7 Cases with vaginal or cervico-vaginal atresia or agenesis and normal uterine corpus. a T2-weighted MR image in a 20-year-old patient with complete cervico-vaginal atresia. Medial sagittal section

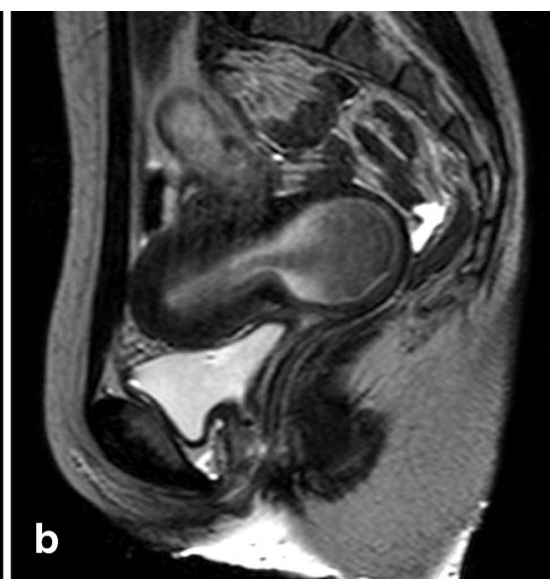

showing the uterus and cervico-vaginal atresia $(<<)$. b T2-weighted sagittal plane in the other case with vaginal atresia and haematocervicometra (courtesy of Dr. MJ. Lázaro, Oviedo) 
Fig. 8 Schematic representation of urogenital sinus and cloacal anomalies. a Congenital vesicovaginal (pseudo)fistula. b Cloacal malformations: cloaca with a short common cannel

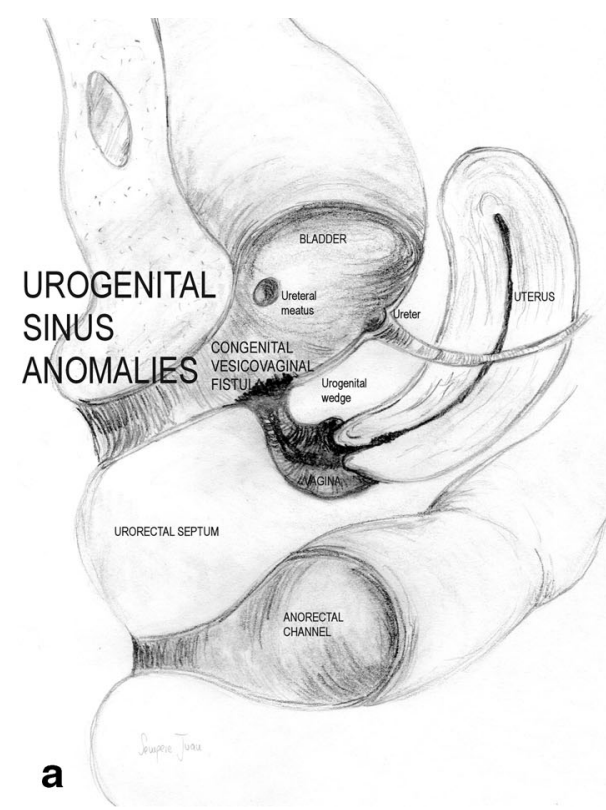

A congenital vesicovaginal fistula is a rare, complex female genital malformation that is difficult to diagnose, classify and treat. Its embryological origin lies in the abnormal persistence of the urogenital sinus due to the lack of formation and caudal growth of the urogenital wedge [8, 15]. This diagnosis should be suspected in any girl with urinary incontinence, urinary tract infections from birth, vaginal swelling or hydrocolpometra and in adults with cyclical menouria and vaginal atresia [65]. Foetal urinary ascites and hydrometrocolpos might be a consequence of persistent urogenital sinus and result of a vesicovaginal

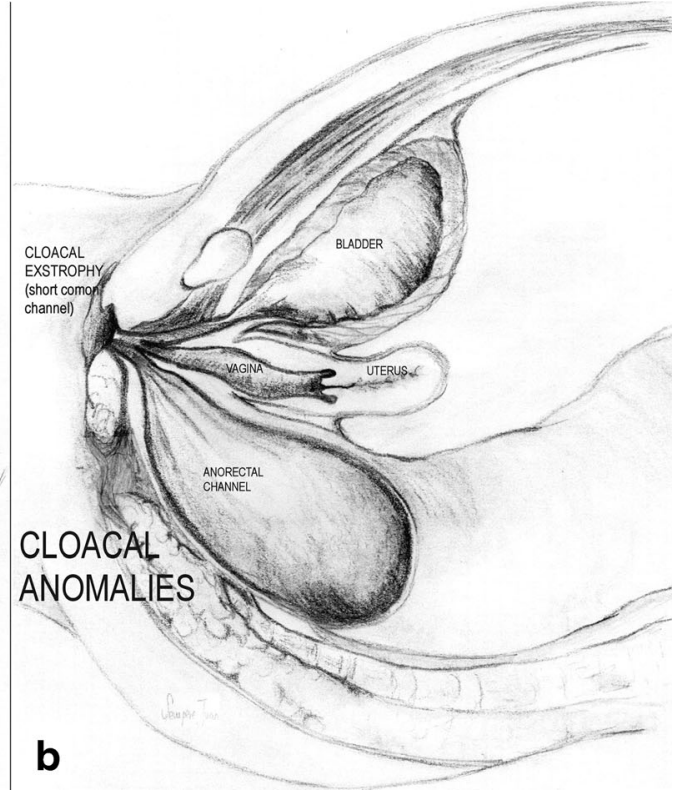

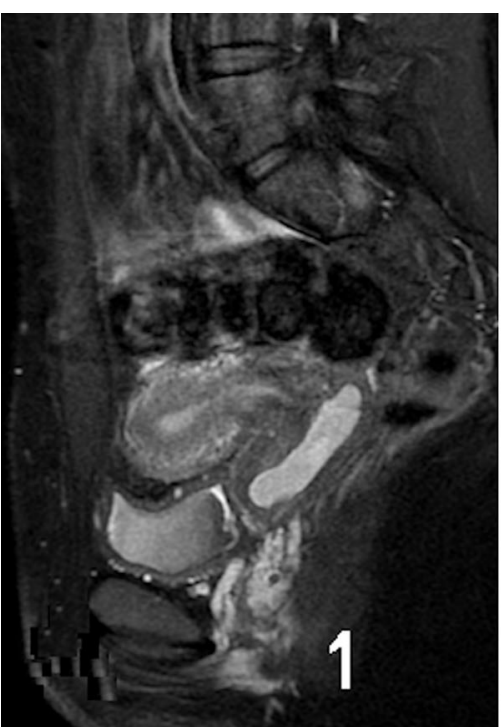

Fig. 9 Urogenital sinus anomalies. MR images [(1) T1- and (2) T2weighted fat-supressed MR in the sagittal plane] showing a retrovesical blind vagina with apparent inferior half atresia and undetected fistula tract to the bladder $(<<)$ in a 28-year-old patient. Cystoscopy confirmed the presence of an orifice situated in the trigone, just above the bladder neck, fistula $[66,67]$. The diagnosis should be based on a high index of suspicion in second trimester US and an MR in the third trimester of pregnancy. However, in adolescent or adult women, the diagnosis should also be based on suspicion, but especially on physical examination, cystoscopy during menouria and imaging (US and MR as shown in Fig. 9) [61].

A rectovestibular fistula often coexists with vaginal or vestibular atresia. Female cloacal exstrophy occurs when the urorectal septum fails to separate from the cloacal membrane, resulting in the urethra, vagina, rectum and anus

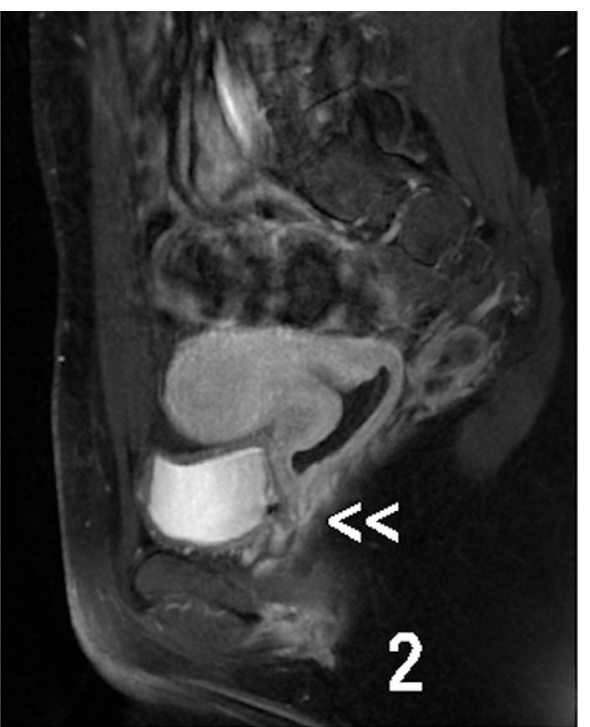

equidistant and below both ureteral meati, through which menstrual blood clearly exited from the vagina. The patient suffered from cyclic menuria and the opening of the fistulous tract into the bladder trigone was in fact the hymen (courtesy of Dr. JC. Martínez-Escoriza, Alicante) 
opening into a single common channel (Fig. 8b). MR could accurately demonstrate the level of bowel termination in patients with persistent cloaca in addition to its high sensitivity for detection of Müllerian anomalies, which are present in $73 \%$ of patients [68].

6. Malformative combinations: Some patients may present several associated anomalies of mesonephric, Müllerian and/or cloacal origin $[9,54,69]$ that result in very complex malformations $[70,71]$ with a rich chart of symptoms that may be difficult to appropriately catalogue and treat, especially if the embryology and physiopathology of the female genital tract is not taken into consideration.

\section{Conclusions}

1. The combination of uterine duplicity and obstructed or blind hemivagina appears to be virtually always associated with ipsilateral renal agenesis or dysgenesis. Imaging tests (IVP, MR) are necessary not only to confirm the absence of a normal kidney on the affected side, but also to detect abnormalities of the contralateral kidney and/or ureter [72].

2. Although cases with normal kidneys have also been described [73, 74], the analysis of what is referred to in these papers shows that there was always some kind of renoureteral anomaly or malrotation [75]. Furthermore, if there is unilateral renal agenesis, there must also be genital malformation with didelphys, bicornuate and more rarely septate uterus (sometimes reported as single uterus [76]), but not necessarily a blind or atretic hemivagina [54, 77]. There could also be cases with partial reabsorption of the vaginal septum, but no case has been reported in the literature with unilateral renal agenesis, normal uterus and vagina.

3. Another controversial point is the differentiation between a bicornuate and a septate uterus. However, the distinction is very important for the treatment of symptomatic patients (abdominal Strassmann metroplasty on the bicornuate uterus versus hysteroscopic resection in cases of septate). TVU, 3D-US and sonohysterography, especially MR, have ushered in a new era of non-invasive diagnosis of uterine anomalies [4-7, 20, 47, 78]. Nevertheless, there are transitional cases between both uterine segments in which fusion defects are associated with resorption defects and these situations must also be recognised before a therapeutic decision can be made.

Acknowledgments To Dr. M. Sánchez-Ferrer, Murcia; Dr. MJ. Lázaro, Oviedo and Dr. JC. Martínez-Escoriza, Alicante, who gave us Figs. 3d, 7b and 9 respectively. No funding. Conflict of Interest: The authors declare that they have no conflict of interest. Ethical approval: All procedures performed in studies involving human participants were in accordance with the Ethical Standards of the Institutional and/or National Research Committee and with the 1964 Helsinki Declaration and amendments or comparable ethical standards. Details of Ethics Approval: The authors have the signed consent of the patients whose images are included or the permission of those whose were previously published.

Open Access This article is distributed under the terms of the Creative Commons Attribution 4.0 International License (http:// creativecommons.org/licenses/by/4.0/), which permits unrestricted use, distribution, and reproduction in any medium, provided you give appropriate credit to the original author(s) and the source, provide a link to the Creative Commons license, and indicate if changes were made.

\section{References}

1. Saravelos SH, Cocksedge KA, Li TC (2008) Prevalence and diagnosis of congenital uterine anomalies in women with reproductive failure: a critical appraisal. Hum Reprod Update 14:415-429

2. March CM (1990) Müllerian anomalies. Fertility news 24/1. Endocr Fert Forum 13:1

3. Acién P (1997) Incidence of Müllerian defects in fertile and infertile women. Hum Reprod 12:1372-1376

4. Pellerito JS, McCarthy SM, Doyle MB, Glickman MG, DeCherney AH (1992) Diagnosis of uterine anomalies: relative accuracy of MR imaging, endovaginal sonography, and hysterosalpingography. Radiology 183:795-800

5. Saleem SN (2003) MR imaging diagnosis of uterovaginal anomalies. current state of the art. RadioGraphics 23:e13

6. Behr SC, Courtier JL, Qayyum A (2012) Imaging of Müllerian duct anomalies. RadioGraphics 32:E233-E250

7. Berger A, Batzer F, Lev-Toaff A, Berry-Roberts C (2014) Diagnostic imaging modalities for Müllerian anomalies: the case for a new gold standard. J Minim Invasive Gynecol 21:335-345

8. Acién P, Acién MI (2011) The history of female genital tract malformation classifications and proposal of an updated system. Hum Reprod Update 17:693-705

9. Acién P (1992) Embryological observations on the female genital tract. Hum Reprod 7:437-445

10. Acién P, Acién MI, Sánchez-Ferrer M (2004) Complex malformations of the female genital tract. New types and revision of classification. Hum Reprod 10:2377-2384

11. Sánchez-Ferrer ML, Acién MI, Sánchez del Campo F, Mayol-Belda MJ, Acién P (2006) Experimental contributions to the study of the embryology of the vagina. Hum Reprod 21:1623-1628

12. Acién M, Acién P (2013) Classification of the female genital tract malformations and its embryological origin. Diagnostic and therapeutical considerations. Curr Women's Health Rev 9:1-29

13. Acién P, Sánchez del Campo F, Mayol MJ, Acién MI (2011) The female gubernaculum: role in the embryology and development of the genital tract and in the possible genesis of malformations. Eur J Obstet Gynecol 159:426-432

14. Acién P, Acién MI, Sanchez-Ferrer ML (2009) Mullerian anomalies "without a classification": from the didelphys-unicollis uterus to the bicervical uterus with or without septate vagina. Fertil Steril 91: 2369-2375

15. Acién P, Acién M (2016) The presentation and management of complex female genital malformations. Hum Reprod Update 22:48-69

16. Strassmann P (1907) Die operative Vereinigung eines doppelten Uterus. Zentralbl f Gynäk 31:1322

17. Jarcho J (1946) Malformations of the uterus. Am J Surg 714:106-166

18. Buttram VC (1983) Müllerian anomalies and their management. Fertil Steril 40:159-163 
19. American Fertility Society (1988) The American Fertility Society classifications of adnexal adhesions, distal tubal occlusion, tubal occlusion secondary to tubal ligation, tubal pregnancies, Müllerian anomalies and intrauterine adhesions. Fertil Steril 49:944-955

20. Chandler TM, Machan LS, Cooperberg PL, Harris AC, Chang SD (2009) Müllerian duct anomalies: from diagnosis to intervention. Pictorial review. Brit J Radiol 82:1034-1042

21. Grimbizis GF, Campo R, Gordts S, Brucker S, Gergolet M, Tanos V et al (2012) Clinical approach for the classification of congenital uterine malfomations. Gynecol Surg 9:119-129

22. Grimbizis GF, Gordts S, Spiezio Sardo A, Brucker S, De Angelis C, Gergolet M et al (2013) The ESHRE/ESGE consensus on the classification of female genital tract congenital anomalies. Hum Reprod 28:2032-2044

23. Goldberg JM, Falcone T (1996) Double cervix and vagina with a normal uterus: an unusual Müllerian anomaly. Hum Reprod 11: 1350-1351

24. Chang AS, Siegel CL, Moley KH, Ratts VS, Odem RR (2004) Septate uterus with cervical duplication and longitudinal vaginal septum: a report of five new cases. Fertl Steril 81:1133-1136

25. Pavone ME, King JA, Vlahos N (2006) Septate uterus with cervical duplication and a longitudinal vaginal septum: a Müllerian anomaly without a classification. Fertil Steril 85:494.e9-10

26. Muller P, Dellenbach P, Gillet JY (1967) Malformations of the female genital tract and those of the upper urinary tract which may be associated with them: morphological and physiopathological study. Sem Hop 43:912-918

27. Jones WS (1953) Congenital anomalies of the female genital tract. Trans N Engl Obstet Gynecol Soc 7:79-94

28. King LA, Sanchez-Ramos L, Talledo OE, Reindollar RH (1987) Syndrome of genital, renal, and middle ear anomalies: a third family and report of a pregnancy. Obstet Gynecol 69:491-493

29. Acién P, Galán F, Manchón I, Ruiz E, Acién MI, Alcaraz LA (2010) Hereditary renal adysplasia, pulmonary hypoplasia and MayerRokitansky-Kuster-Hauser (MRKH) syndrome. A case report. Orphanet J Rare Dis 5:6

30. Spencer R, Levy DM (1962) Hydrometrocolpos: report of three cases and review of the literature. Ann Surg 155:558-571

31. Rosenberg HK, Udassin R, Howell C, Betts J, Schnauffer L (1982) Duplication of the uterus and vagina, unilateral hydrometrocolpos, and ipsilateral renal agenesis: sonographic aid to diagnosis. $\mathrm{J}$ Ultrasound Med 1:289-291

32. Acién P, García-López F, Ferrando J, Chehab HE (1990) Single ectopic ureter opening into blind vagina, with renal dysplasia and associated utero-vaginal duplication. Int J Gynecol Obstet 31:179-185

33. Acién P, Susarte F, Romero J, Galán J, Mayol MJ, Sánchez-Ferrer M (2004) Complex genital malformation: ectopic ureter ending in a supposed mesonephric duct in a woman with renal agenesis and ipsilateral blind hemivagina. Eur J Obstet Gynecol Reprod Biol 117:105-108

34. Gadbois WF, Duckett JW (1974) Gartner's duct cyst and ipsilateral renal agenesis. J Urol 4:720-721

35. Herlyn U, Werner H (1971) Das gemeinsame vorkommen von offener gartner-gang-zyste, gleichseitiger nierenaplasie und uterusdoppel-mißbildung als typisches mißbildungssyndrom. Geburtsh u Frauenheilkd 31:340-347

36. Ruiz E, Pastor J, Galera L (1999) Útero doble con ausencia unilateral de cérvix: hallazgos en la tomografía computarizada y la resonancia magnética. Clin Invest Gin Obstet 26:235-238

37. Acién P, Sánchez-Ferrer ML, Mayol-Belda MJ (2004) Unilateral cervico-vaginal atresia with ipsilateral renal agenesis. Eur J Obstet Gynecol Reprod Biol 117:249-251

38. Acién P, Acién M, Fernandez S (2008) Segmentary atresias in Müllerian malformations. Eur J Obstet Gynecol Reprod Biol 141: 188-189

39. Bermejo C, Martínez-Ten P, Recio M, Ruiz-López L, Diaz D, Illescas T (2014) Three-dimensional ultrasound and magnetic resonance imaging assessment of cervix and vagina in women with uterine malformations. Ultrasound Obstet Gynecol 43:336-345

40. Pizzo A, Laganà AS, Sturlese E, Retto G, Retto A, De Dominici R, Puzzolo D (2013) Mayer-Rokitansky-Kuster-Hauser syndrome: embryology, genetics and clinical and surgical treatment. ISRN Obstetr Gynecol 628717:1-10

41. Oppelt PG, Lermann J, Strick R, Dittrich R, Strissel P, Rettig I et al (2012) Malformations in a cohort of 284 women with MayerRokitansky-Küster-Hauser syndrome (MRKH). Reprod Biol Endocrinol 10:57-64

42. Fiaschetti V, Taglieri A, Gisone V, Coco I, Simonetti G (2012) Mayer-Rokitansky-Kuster-Hauser syndrome diagnosed by magnetic resonance imaging. role of imaging to identify and evaluate the uncommon variation in development of the female genital tract. $\mathrm{J}$ Radiol Case Rep 6:17-24

43. Acién P, Lloret M, Chehab H (1988) Endometriosis in a patient with Rokitansky-Kuster-Hauser syndrome. Gynecol Obstet Invest 25: 70-72

44. Yoo RE, Cho JY, Kim SY, Kim SH (2013) Magnetic resonance evaluation of Müllerian remnants in Mayer-Rokitansky-KüsterHauser syndrome. Korean J Radiol 14:233-239

45. Grimbizis GF, Mikos T, Papanikolaou A, Theodoridis T, Tarlatzis BC (2015) Successful isthmo-neovagina anastomosis after Davydov's colpopoiesis in Mayer-Rokitansky-Küster-Hauser syndrome patients with a functional rudimentary uterine horn. J Minim Invasive Gynecol 22:142-150

46. Robbins JB, Broadwell C, Chow LC, Parry JP, Sadowski EA (2015) Müllerian duct anomalies: embryological development, classification, and MRI assessment. J Magn Reson Imaging 41:112

47. Graupera B, Pascual MA, Hereter L, Browne JL, Úbeda B, Rodríguez I, Pedrero C (2015) Accuracy of three-dimensional ultrasound compared with magnetic resonance imaging in diagnosis of Müllerian duct anomalies using ESHRE-ESGE consensus on the classification of congenital anomalies of the female genital tract. Ultrasound Obstet Gynecol. doi:10.1002/uog.14825

48. Acién P, Acién M, Quereda F, Santoyo T (2008) Cervicovaginal agenesis: spontaneous gestation at term after previous reimplantation of the uterine corpus in neovagina. Hum Reprod 23:548-553

49. Celayir AC, Kurt G, Sahin C, Cici I (2013) Spectrum of etiologies causing hydrometrocolpos. J Neon Surg 2(1):5

50. Nazir Z, Rizvi RM, Qureshi RN, Khan ZS, Khan Z (2006) Congenital vaginal obstructions: varied presentation and outcome. Pediatr Surg Int 22:749-753

51. Acién P, Acién MI, Fernández F, Mayol MJ, Aranda I (2010) The cavitated accesory uterine mass: a Müllerian anomaly in women with an otherwise normal uterus. Obstet Gynecol 116:1101-1109

52. Acién P, Bataller A, Fernández F, Acién MI, Rodriguez JM, Mayol MJ (2012) New cases of accessory and cavitated uterine masses (ACUM): a significant cause of severe dysmenorrhea and recurrent pelvic pain in young women. Hum Reprod 27:683-694

53. Jain N, Verma R (2014) Imaging diagnosis of accesory and cavitated uterine mass, a rare Müllerian anomaly. Indian J Radiol Imaging 24:178-181

54. Acién P, Acién M, Romero-Maroto J (2010) Blind hemibladder, ectopic ureterocele, or Gartner's duct cyst in a woman with Müllerian malformation and supposed unilateral renal agenesis: a case report. Int Urogynecol J 21:365-369

55. Kajbafzadeh AM, Amini E, Javan-Farazmand N, Sahebpour AA (2013) Complex genito urinary duplication affecting neurourologic and urodynamic findings: report of a case and review of the literature. J Pediatr Adolesc Gynecol 26:e109-e111

56. de León-Luis J, Pérez L, Pérez R, Bravo C, Parente A, Gámez F et al (2014) Prenatal diagnosis of incomplete bladder duplication: sonopraphic features and perinatal management. J Ultrasound Med $33: 358-361$ 
57. Singh BP, Pathak HR, Andankar MG (2010) Bilateral singlesystem ectopic ureters opening into vaginalized urogenital sinus. Indian J Urol 26:126-128

58. Chen CY, Tsao TF, Chang HM, Chen SL, Chen SM, Hung TW, Lue KH, Sheu JN (2012) Bladder agenesis and bilateral ectopic ureters draining into the vagina in a female infant: demonstrated by MR imaging. Surg Radiol Anat 34:89-92

59. Baheti V, Singh J, Yadav SS, Tomar V (2014) Bilateral single ectopic ureters opening into vestibule with bladder agenesis. Int Urol Nephrol 46:1253-1255

60. Martínez-Escoriza JC, Lobato JJ, Lorda E, De Vera M, Moya A, Ramirez R, Sánchez OP (2011) Congenital vesicovaginal fistula with menouria: an anomaly of the urogenital sinus. Eur J Obstet Gynecol Reprod Biol 159:472-475

61. Martínez-Escoriza JC, Palacios-Marqués AM, López-Fernández JA, Feliu-Rey E, Martín-Medina P, Herráiz-Romero I et al (2014) Congenital vesicovaginal fistula with or without menouria: a literature review. Eur J Obstet Gynecol Reprod Biol 175:38-48

62. Levitt MA, Peña A (2010) Cloacal malformations: lessons learned from 490 cases. Sem Pediat Surg 19:128-138

63. Couchman A, Creighton SM, Wood D (2015) Adolescent and adult outcomes in women following childhood vaginal reconstruction for cloacal anomaly. J Urol 193(5 Suppl):1819-1823

64. Gibbens JD, Morton M, Villanueva CA, Satpathy H (2015) Antepartum diagnosis of complete fetal bladder duplication in the sagittal plane. J Ultrasound Med 34:737-739

65. Kashimura T, Takahaschi S, Nakazawa H (2012) Successful management of a thick transverse vaginal septum with a vesicovaginal fistula by vaginal expansion and surgery. Int Urogynecol J 23:797799

66. Nigam A, Kumar M, Gulati S (2014) Fetal ascites and hydrometrocolpos due to persistent urogenital sinus and cloaca: a rare congenital anomaly and review of literature. BMJ Case Rep

67. Loganathan P, Kamaluddeen M, Soraisham AS (2014) Urinary ascites due to persistent urogenital sinus: a case report and review of literature. J Neonatal Perinatal Med 7:75-79

68. Mohammad SA, AbouZeid AB (2013) MRI of persistent cloaca: can it substitute conventional imaging? Eur J Radiol 82:241-251

69. Acién P, Acién MI (2010) Unilateral renal agenesis and female genital tract pathologies. Acta Obstet Gynecol Scand 89:1424-1431
70. Dannull K, Sung J (2014) Cloacal dysgenesis diagnosis by prenatal ultrasound and MRI. Pediatr Radiol 44:230-233

71. Iglesias-Lopes R, Tibor-Dénes F, Padovani G, Sircili MH, Srougi M (2014) Monti's Principle in the treatment of congenital uterovesical fistula. Urology. Doi j.urology.2013.12.040

72. Stassart JP, Nagel TC, Prem KA, Phipps WR (1992) Uterus didelphys, obstructed hemivagina, and ipsilateral renal agenesis: the University of Minnesota experience. Fertil Steril 57:756-761

73. Smith NA, Laufer MR (2007) Obstructed hemivagina and ipsilateral renal anomaly (OHVIRA) syndrome: management and followup. Fertil Steril 87:918-922

74. Johnson J, Hillman BJ (1986) Uterine duplication, unilateral imperforate vagina, and normal kidneys. AJR Am J Roentgenol 147: $1197-1198$

75. Heinonen PK (2000) Clinical implications of the didelphic uterus: long-term follow-up of 49 cases. Eur J Obstet Gynecol Reprod Biol 91:183-190

76. Shah DK, Laufer MR (2011) Obstructed hemivagina and ipsilateral renal anomaly (OHVIRA) syndrome with a single uterus. Fertil Steril 96:e39-e41

77. Heinonen PK (2006) Complete septate uterus with longitudinal vaginal septum. Fertil Steril 85:700-705

78. Yoo RE, Cho JY, Kim SY, Kim SH (2015) A systematic approach to the magnetic resonance imaging-based differential diagnosis of congenital Müllerian duct anomalies and their mimics. Abdom Imaging 40:192-206

\section{Highlights}

The appropriate cataloguing of female genital malformations, especially in complex cases, is controversial. However, an embryological classification system suggests the best diagnosis and appropriate management.

The anomalies most frequently wrongly diagnosed are those included in group II of the embryological and clinical classification (distal mesonephric anomalies), being associated with unilateral renal agenesis or renal dysplasia with an ectopic ureter. Other complex malformations include cervico-vaginal agenesis, cavitated uterine horns, cloacal and urogenital sinus anomalies, and malformative combinations.

Diagnostic imaging for all these anomalies is essential. 